\title{
The separation of tertiary butyl alcohol in methyl tertiary butyl ether dis- tillation desulfurization process
}

\author{
C.F. Zhang ${ }^{1, a}$, Q.M. Jia ${ }^{1, b}$, J.M. Zhang ${ }^{2, c}$ \\ ${ }^{1}$ Faculty of Chemical Engineering, Kunming University of Science and Technology, Kunming \\ 650504, China \\ ${ }^{2}$ Jinzhou Design Institute, CNPC Northeast Refining \& Chemicals Engineering Company Limited, \\ Jinzhou 121001,China

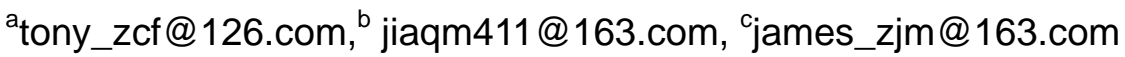

Keywords: Methyl tertiary butyl ether; Tertiary butyl alcohol; Simulation; Desulfurization process

\begin{abstract}
Researches on methyl tertiary butyl ether(MTBE) distillation desulfurization process are very common now, but the influence of the separation of tertiary butyl alcohol(TBA) in MTBE on this process was seldom reported. This paper analyzes the 2-column MTBE distillation desulfurization process in detail by using the PRO/II simulation software. The best sulfides content in MTBE and more suitable operating parameters of the second column which carries on TBA separation have been determined exactly. It suggested that the best sulfides content index value in MTBE be $10 \mathrm{mg} / \mathrm{kg}$. The optimal MTBE distillation desulfurization process can make the recovery of TBA up to $99 \%$ by weight and remain the sulfides content index value in MTBE at the level of $10 \mathrm{mg} / \mathrm{kg}$ steadily.
\end{abstract}

\section{Introduction}

The desulfurization process of methyl tertiary butyl ether(MTBE) used as a gasoline additives has received attentions in recent years as a necessary process to make the sulfides content of MTBE meet the National 5th Stage Motor Vehicle Gasoline Standard. The desulfurization process can be classified as LPG fine desulfurization[1] and MTBE distillation desulfurization[2]. Tertiary butyl alcohol(TBA) in MTBE does not needed to be separated in LPG fine desulfurization because it can be added to gasoline with its octane number is 97. But it should be studied in MTBE distillation desulfurization to show if it is necessary to recover TBA in MTBE as impurity.

Researches on MTBE distillation desulfurization process focused on desulfurization, energy conservation and increasing the recovery of MTBE these years[3-4].The 2-column MTBE distillation desulfurization process became hot on the basis of lower energy cost and higher recovery of MTBE[5]. Some new technologies have been patented recently [6-7]. However the influence of the separation of TBA in MTBE on these processes was never reported. This paper will discuss the separation law of TBA to develop more suitable MTBE distillation desulfurization process.

\section{The components of mtbe product}

The purity of MTBE is about $98.5 \%$ by weight which includes some impurities such as methanol, sec-Butyl Methyl Ether, diisobutylene, TBA and sulfides consisting of dimethyldisulfide, tertbutyl ethyl sulfide, n-butyl mercaptan and thiophene. Tab.1 shows the components and properties of MTBE. 
Tab.1 Components and boiling points of MTBE product

\begin{tabular}{ccc}
\hline components & content/wt\% & Boiling points $/{ }^{\circ} \mathrm{C}$ \\
\hline MTBE & 98.5 & 55.2 \\
methanol & 0.15 & 64.5 \\
MSBE & 0.45 & 75 \\
TBA & 0.50 & 82.4 \\
diisobutylene & 0.30 & 101.4 \\
sulfides & 0.01 & 98.9 \\
\hline
\end{tabular}

Note: sulfides indicate tertbutyl ethyl sulfide

TBA is produced by reacting isobutene with water in the presence of acidic ion-exchange resins:

$$
\mathrm{CH}_{2}=\mathrm{C}\left(\mathrm{CH}_{3}\right)_{2}+\mathrm{H}_{2} \mathrm{O}=\mathrm{CH}_{3}-\mathrm{C}\left(\mathrm{CH}_{3}\right)_{2} \mathrm{OH}
$$

It reacted easily with higher selectivity only if water exists[8]. Water may come from raw materials such as mixed $\mathrm{C}_{4}$ fraction ,catalyst, fresh methanol and recycling methanol. Water should be controlled to cut the production of TBA[9]. Tab.2 shows moisture content in raw materials.

Tab2. Moisture content in raw materials

\begin{tabular}{cc}
\hline source & moisture content/wt\% \\
\hline mixed $\mathrm{C}_{4}$ & $\ngtr 0.0005$ \\
fresh methanol & $\ngtr 0.1$ \\
recycling methanol & $\ngtr 0.5$ \\
\hline
\end{tabular}

\section{Process simulation and method}

This paper studies the separation law of TBA based on the 2-column MTBE distillation desulfurization process. Fig.1shows the process flowsheet. The column T-101 is the $1^{\text {st }}$ desulfurization column and T-102 is the $2^{\text {nd }}$ one. Process simulation on T-102 is the key point because the separation of TBA is carried on mainly in it. Tab. 3 shows the operating parameters of T101 which should be determined at first.

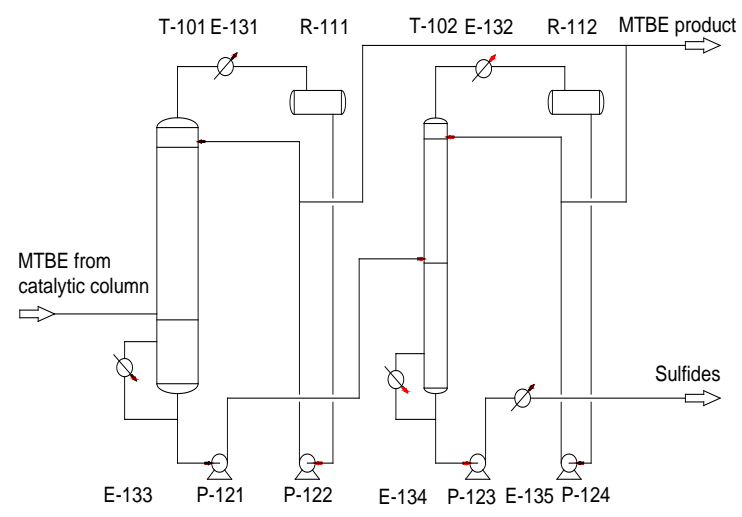

Fig.1 2-column MTBE desulfurization process flowsheet

Tab3. Operation parameters of T-101

\begin{tabular}{cccc}
\hline column & $\begin{array}{c}\text { theoretical } \\
\text { plate }\end{array}$ & $\begin{array}{c}\text { Kettle tempera- } \\
\text { ture } /{ }^{\circ} \mathrm{C}\end{array}$ & sulfides content \\
\hline $\mathrm{T}-101$ & 20 & 70 & $\leqslant 3 \mathrm{mg} / \mathrm{kg}$ \\
\hline
\end{tabular}

The process was simulated with PRO//II V8.1software. Wilson equation was chosen as thermodynamic method. The sulfides content index value in MTBE was set within $10 \mathrm{mg} / \mathrm{kg}$ through the process. The relations between theoretical plates of T-102 and the reboiler heat load of T-102 based on $10 \times 10^{6} \mathrm{t} \cdot \mathrm{a}^{-1}$ MTBE unit was studied when the recovery of TBA reaches $99 \%$ by 
weight and the suitable number of theoretical plates was given. The relations between the reboiler heat load and the TBA's recovery was studied as well under this theoretical plates number. Then the more suitable separation parameters were obtained finally.

\section{Results and discussion}

Fig. 2 shows that how heat load changes with the theoretical plates of T-102 while the TBA's recovery is set to $99 \%$ by weight.

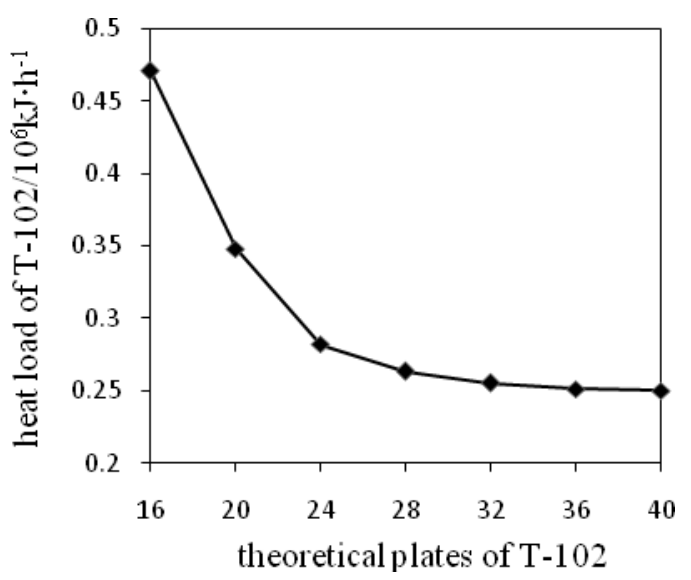

Fig.2 Heat load changes with the theoretical plates of T-102

Fig. 2 proves that heat load decreases with the theoretical plates increasing. Heat load drops sharply when the number of theoretical plates are less than 28 and gently when the number is more than 28. Heat load will almost not change when the theoretical plates are over 36. So the theoretical plates of T-102 should be 36 . Under this situation, we studied the relations between heat load and TBA's recovery of T-102(see Fig.3).

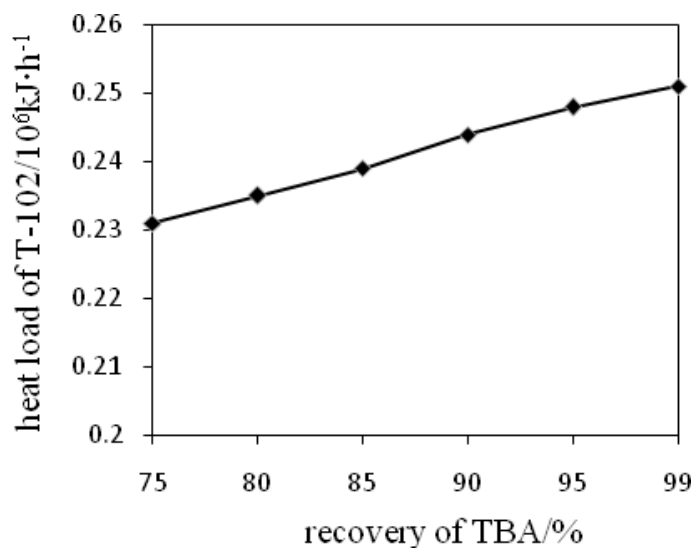

Fig.3 Heat load changes with the recovery of TBA

Fig.3 indicates that heat load increases linearly with increasing the recovery of TBA. It shows that unit energy consumption of TBA's recovery remains constant. So TBA should be recovered furthest to improve MTBE output and the recovery should not be lower than 99\% by weight.

Zhang suggested in his paper that the theoretical plates of T-102 should be 20 [10]. The sulfides content in MTBE from T-102 is restricted by $3 \mathrm{mg} / \mathrm{kg}$. So the final sulfides content in MTBE product is near to $3 \mathrm{mg} / \mathrm{kg}$ as well which is far less than $10 \mathrm{mg} / \mathrm{kg}$. In order to get lower sulfides content index value of MTBE,TBA's recovery has to be decreased by $30 \%$ by weight because of bad separation effect of T-102. Then MTBE output was cut down in fact. The optimal process suggests that the best sulfides content in MTBE product be $10 \mathrm{mg} / \mathrm{kg}$, the sulfides content index value given by the new national standard, which means that the sulfides content from T-102 could 
be far more than 3mg/kg through increasing the recovery of TBA. Then more MTBE product and profit were obtained simultaneously.

\section{Conclusions}

The best sulfides content index value of MTBE product should be raised to $10 \mathrm{mg} / \mathrm{kg}$. MTBE output can be increased by improving the recovery of TBA which should not be less than 99\% by weight. The theoretical plates of T-102 will add to 36 to enhance separation effect. The optimal 2column MTBE distillation desulfurization process may ensure that TBA's recovery is more than $99 \%$ by weight and the sulfides content in MTBE remains at the level of $10 \mathrm{mg} / \mathrm{kg}$ steadily.

\section{Acknowledgement}

Financial supports from Chinese National Petroleum Corporation(2010E-2010) are acknowledged.

\section{References}

[1] Deng C.L.2012 Master thesis. East China University of Science and Technology.

[2] Dong W.G., Wang Y.\& Hu X.S. 2014 China. Patent 104098448A.

[3] Ke M., Yu P. \& Song Z.Z. 2012 China. Patent 102557888A.

[4] Li W.Z. 2013 etroleum Refinery Engineering. 43: 9.

[5] Lu H.X., Gao Q.B. \& Wang Z.P.2014 Petroleum Refinery Engineering. 44: 1.

[6] Shi Y.C., Sun X.H. \& Hou S.C. 2011 Liaoning Chemical Industry. 40: 845.

[7] Wu W.Z., Han Z.Z. \& Zhang Y.D. 2011 Computers and Applied Chemistry. 28: 991.

[8] Zhang C.F., Jia Q.M. \& Zhang J.M. 2014 Chemical Industry and Engineering Progress. 33: 2215.

[9] Zhang J.M., Zhao J.H. \& Chen J. 2013 Chemical Industry and Engineering Progress. 32:1453.

[10] Zhou G.L., Wu Q.G. \& Zhou H.J. 2013 Modern Chemical Industry, 33: 100. 